\title{
EL MITO DEL ORIGEN EN LA COSMOVISIÓN MAPUCHE DE LA NATURALEZA: UNA REFLEXIÓN EN TORNO A LAS IMÁGENES DE FILU - FILOKO - PIRU
}

\author{
CAROLINA VILLAGRÁNª \& MIGUEL A. VIDELA ${ }^{\mathbf{b}}$
}

\section{RESUMEN}

Se indaga en torno a la peculiar concepción de naturaleza de la cultura mapuche y se enfatiza el rol central que juega el mito del origen en dicha cosmovisión. En particular, se reflexiona acerca del significado de la imagen de la serpiente, filu, y su representación analógica en figuras de animales relacionados, especialmente en la percepción de catástrofes y desequilibrios del orden natural. Se destaca la importancia de estos nexos en la concepción de variados aspectos del mundo físico, biológico y cultural, sea en la denominación del espacio geológico-geográfico; sea en la nomenclatura y clasificación de las plantas y de los animales; sea en los modos de actividades de subsistencia; sea en la concepción de la génesis y tratamiento de enfermedades; sea en los ritos, costumbres y religiosidad de la comunidad. Como un ejemplo de la participación del mito del origen en actividades tradicionales, se detallan algunos rasgos legendarios asociados a la captura de la lamprea, en lengua mapudungun filoko; en esta misma línea, se revisa la etnohistoria en torno a la palabra "gusano", piru, y su vinculación a la etiología de enfermedades, de acuerdo al modelo de la medicina mapuche. Finalmente, se subraya el valor heurístico que tiene el espacio simbólico abarcado por el saber indígena de la naturaleza, (i) tanto en el dominio reflexivo de la antropología, historia, sociología y ciencias naturales, (ii) como asimismo en la forma de habitar el entorno natural y (iii) en la educación interdisciplinaria e intercultural.

PALABRAS CLAVE: mito, naturaleza, serpiente, lamprea, gusano.

\section{THE MYTH OF THE ORIGIN IN THE MAPUCHE WORLDVIEW A REFLECTION ABOUT THE IMAGES OF FILU-FILOKO-PIRU}

\begin{abstract}
We discuss the singular conception of nature embedded in the Mapuche culture, emphasizing the central role that the myth of origin plays in the Mapuche worldview. In particular, we reflect about the image of the serpent, filu, and its symbolic representation, by analogy, in the forms of related animals, especially in the perception of natural catastrophes and disequilibrium of the natural order. We remark

a Departamento de Biología, Universidad de Chile. $\triangle$ carolinavillagran.moraga@gmail.com

b Museo Nacional de Odontología. betancurtvidela@hotmail.com
\end{abstract}


on the importance of these symbolic links for the conception of several aspects of the physical, biological and cultural world of the Mapuche: be it the geologic-geographic domain; be it the denomination and classification of animals and plants, the mode of subsistence, the understanding of the source and treatment of diseases; be it the rituals, customs, and religiosity of the community. As an example of the inclusion of the myth of origin in traditional activities, we point out some symbolic features associated with the capture of lamprey, filoko in the Mapudungun language; in the same vein, we review the ethno-history around the term for worm, piru in Mapudungun, and its relationship to the etiology of human diseases. Finally, we underline the heuristic value of the symbolic space derived from the Mapuche knowledge of nature, considering (i) the reflexive domains of anthropology, history, sociology and natural science, (ii) the form of inhabiting the natural surroundings, and (iii) the interdisciplinary and inter-cultural education

KEY WORDS: Myth, serpent, lamprey, worm.

\section{EL SÍMBOLO DE LA SERPIENTE EN EL MITO DEL ORIGEN}

¿Qué es un símbolo? Decir una cosa y significar otra. ¿Por qué no decirlo directamente? Por la simple razón de que ciertos fenómenos tienden a disolverse si nos acercamos a ellos sin ceremonia. E. Wind ${ }^{1}$

Podríamos decir que ahi donde el impotente sufrimiento humano comienza a buscar la salvación, la serpiente como imagen y como explicación de la causalidad no está muy alejada. A. Warburg ${ }^{2}$

En las últimas décadas se ha difundido la idea de que se puede entregar una explicación causal de los acontecimientos que relatan los mitos (del griego $\mu \tilde{\theta} \theta$ os, mythos, "relato") $)^{3}$, principalmente en referencia a eventos geológicos. Prueba de ello es el incremento en la búsqueda de las causas del origen de mitos de diversas etnias y el desarrollo de una ya activa línea de investigación geológica en torno a relatos, que se han dado en llamar "geomitos" 4 (Geomyths, Masse \& Masse, 2004; Masse et al. 2007; Vitaliano, 2007). Estos y otros autores (PetitBreuilh, 2006) revisan varios mitos cosmogónicos de Sudamérica y el mundo y su relación con catástrofes naturales, principalmente diluvios,

1 Ruiz, 1995, epígrafe introductorio de su obra.

2 Conferencia dictada por el historiador de arte Aby Warbug, el 21 de abril de 1923, sobre el ritual de la serpiente entre los indios Pueblo de Norteamérica.

3 Barthes, 1957, p. 108: “¿Qué es un mito en la actualidad? Daré una primera respuesta muy simple, que coincide perfectamente con su etimología: el mito es un habla".

4 Geomitología: Estudio de las causas de tradiciones orales vulcanismo y tsunamis. Ya muy tempranamente en Chile, Lenz (1912) documenta relatos mapuches vinculados a maremotos, erupciones volcánicas y terremotos. Indudablemente, hay una fuerte resonancia de estos eventos geológicos en el cataclismo que el mito originario del pueblo mapuche relata, -un combate entre una serpiente acuática caicaivilu y una terrestre tentenvilu-, como lo han destacado algunos de los autores citados. Una versión abreviada de este mito, del cual hay múltiples variantes y en un amplio ámbito geográfico, la proporciona Lévi-Strauss:

En tiempos muy antiguos un diluvio destruyó la humanidad. [...] lo imputan a una serpiente monstruosa, ama del océano, llamada caicai [...]. Huyendo del ascenso de las aguas $y$ de la oscuridad que reinaba, los humanos cargados de viveres subieron a una montaña de cima triple, que pertenecía a otra serpiente, enemiga de la primera. Se llamaba tenten, [...] Quienes no treparon suficientemente aprisa perecieron ahogados, se mudaron en peces de especies variadas que, más tarde, fecundaron a las mujeres acudidas a pescar durante la marea baja. Así fueron concebidos los antepasados de los clanes que tienen nombres de peces. [...] A medida que los sobrevivientes se elevaban

creadas por culturas pre-científicas para explicar fenómenos geológicos tales como volcanes, sismos, inundaciones, fósiles u otros rasgos naturales del paisaje. Masse \& Masse, 2004, p. 10: "myth is a specific style of story created by cultural knowledge specialists [e.g., priests or historians] using supernatural images in order to explain otherwise inexplicable natural events or processes". 
por el flanco de la montaña, ésta se elevaba o, según otras versiones, flotaba en la superficie de las aguas. [...] Cuando caicai se declaró vencida, no quedaba más que una o dos parejas sobrevivientes. Un sacrificio humano les permitió obtener el descenso de las aguas. Y repoblaron la tierra (1968, p. 153).

Evidentemente, hay una conexión en la percepción de procesos geológicos naturales y la narración mapuche del origen, especialmente en una región como Chile, particularmente afectada por intensa actividad tectónica vinculada a su posición en el borde activo de la Placa Sudamericana. Hay una larga y documentada historia de recurrentes terremotos, maremotos y erupciones volcánicas que han perturbado al territorio durante gran parte del Cuaternario; también de fallas tectónicas y eventos glaciotectónicos asociados agrandes reconfiguraciones geográficas y notables fluctuaciones de los niveles del mar durante los ciclos glacial-interglaciales del Pleistoceno. Estos acontecimientos han modelado la actual línea de costa y dejado una fuerte impronta en la accidentada geografía del paisaje actual del sur de Chile. Así, los estudios geomorfológicos (Denton et al. 1999) muestran que la extensión que alcanza el hielo en el Último Máximo Glacial (UMG) en el período tardío de la Glaciación Llanquihue, fechado entre 29.400 y 14.550 C14 años AP, queda evidenciada con precisión en el paisaje actual a través de la nítida traza de cinturones morrénicos, depósitos límnicos y glacio-fluviales, dejados por la actividad glacial. Ello ha dejado la huella de la extensión máxima que alcanzaron las grandes masas de glaciares de piedemonte que descendieron hacia el Valle Longitudinal y excavaron las profundas artesas de los lagos de la así llamada Región de Los Lagos, y de los golfos y fiordos de más al sur, hoy invadidos por el mar. Estos testimonios evidencian la vasta reconfiguración del borde oceánico y el dramático desmembramiento del territorio, en tiempos relativamente muy recientes, y explican la conformación de la actual geografía -la miríada de

5 La definición de mito de Eliade (1963, p. 12), es: El mito cuenta una historia sagrada; relata un acontecimiento que ha tenido lugar en el tiempo primordial, el tiempo lagos, islas, archipiélagos y fiordos que singulariza la distintiva topografía del sur de Chile.

Sin embargo, parece improcedente centrar la interpretación de los mitos sobre la base de una explicación científica que lo focaliza en la ocurrencia de acontecimientos naturales particulares, sean tectónicos, glaciales o naturalistas. Habría que tener en consideración que los mitos constituyen representaciones alternativas de la realidad, y que el universo simbólico al que abarcan difiere de la concepción de naturaleza, causalidad, tiempo e historia, que tiene la ciencia occidental. En efecto, el pensamiento mítico referente a los fenómenos naturales no corresponde al concepto formal de naturaleza, ni a la causalidad mecánica de las ciencias naturales modernas. La formación del mito implica un tipo de pensamiento causal, donde los fenómenos y objetos naturales son personalizados mediante un proceso de simbolización que los conforma a imagen de la percepción humana. De acuerdo a Eliade ${ }^{5}$ (1963), el tiempo "sagrado" del mito, primordial e indefinidamente recuperable, es cualitativamente diferente al tiempo profano, cronológico e irreversible, que marca los acontecimientos en la historia del hombre moderno. Así, el mito contiene en sí mismo rasgos de significación complejos y múltiples, en renovación constante, según el contexto en que se desarrolla. De acuerdo a Barthes, el mito no puede definirse ni por su objeto ni por su materia, puesto que cualquier materia puede ser dotada arbitrariamente de significación (1957, p. 108). Para esclarecer su estructura, se necesita saber cómo funciona su dinámica, qué representa en las relaciones sociales, y qué uso y función tiene en la comunicación interpersonal. De esta manera, sólo puede tener fundamento histórico, pues el mito es un habla elegida por la historia: no surge de la "naturaleza» de las cosas (Ibid., p. 108). Es el mito el que transforma la historia en naturaleza (Ibid., p. 120). Así, cuando se trata de relatos míticos, pareciera que lo más importante es enfatizar el sentido funcional del discurso, el efecto subjetivo de acontecimientos naturales recurrentes en la sensibilidad de la comunidad, -y su articulación a

fabuloso de los "comienzos" [...] Es, pues, siempre el relato de una "creación". 
la particular cosmovisión personificada e integrada del entorno físico, biológico y social-, de acuerdo con los principios que esa comunidad tiene del destino humano. En definitiva, no se puede eludir el carácter mítico que el relato tiene, es decir, una representación simbólica articulable sólo de manera analógica a los elementos y/o acontecimientos naturales. Como afirma Rosete: Los símbolos vinculan al hombre con el mundo y con los demás hombres; que gracias al simbolo, que lo sitúa en una red de relaciones, el hombre no se siente extraño en el universo (Rosete, 2006, p. 277).

En este sentido, resulta instructivo examinar el uso del mito que hace Platón en varios de sus diálogos, obra donde quizás se expresa de la manera más paradigmática la tensión entre mythos y logos. Una de esas narraciones, que el autor califica como "relato verosímil" o "probable" (eikòs mythos, Timeo, p. 29d), manifiesta algunas resonancias con el mito del origen del pueblo mapuche y se refiere, por primera vez, a una gran isla desaparecida, Atlántida. En los diálogos Critias y Timeo, el personaje Critias refiere una historia sobre cómo la Atenas primitiva se hunde junto con la Atlántida, cuando se desencadenara la guerra entre ambas regiones, hace 9.000 años AC. ${ }^{6}$ La búsqueda del emplazamiento geográfico de la Atlántida de Platón, y de la causa de su destrucción, ha generado múltiples hipótesis que apuntan a distintas causas geológicas, y a muy diferentes regiones del mundo. La hipótesis más aceptada y difundida es formulada en 1909 por K.

6 Platón 2000-2007, Timeo 25d, Critias 111 a-b: Tras un violento terremoto y un diluvio extraordinario, en un día y una noche terribles, la clase guerrera vuestra [griega] se hundió toda a la vez bajo la tierra y la isla de Atlántida desapareció de la misma manera, hundiéndose en el mar (Timeo $25 \mathrm{~d}$ ). Toda la región (griega) que se interna profundamente en el mar a partir de la tierra firme es como un cabo. [...] Como se produjeron muchas y grandes inundaciones en los nueve mil años [AC] -pues todos esos años transcurrieron desde esa época hasta hoy- [...] en comparación con lo que había entonces, lo de ahora ha quedado -tal como sucede en las pequeñas islas- semejante a los huesos de un cuerpo enfermo, ya que se ha erosionado la parte gorda y débil de la tierra y ha quedado sólo el cuerpo pelado de la región (Critias, $111 \mathrm{a}-\mathrm{b})$.

7 Los resultados probaron conclusivamente que la erupción del Santorini ocurrió alrededor de dos generaciones antes
T. Frost, quien propone que el mito de la Atlántida se inspira en el imperio cretense. En 1960, A. Galanopoulos sugiere que la erupción del Volcán Hera-Santorini en el Mar Egeo, durante la Edad de Bronce, sería la causa geológica de la destrucción de la civilización de la Creta Minoica, acontecimiento histórico al que se referiría el mito platónico de la abrupta desaparición de la Atlántida. Sin embargo, las evidencias arqueológicas procedentes de las distintas capas de cenizas de la erupción del Volcán Hera-Santorini, fechadas radiocarbónicamente -como asimismo las evidencias arqueológicas, también fechadas, procedentes de Creta y Melosno evidencian correlación entre la erupción y la desaparición de la civilización minoica o cretense (Vitaliano, 2007) ${ }^{7}$. A regañadientes, esta autora reconoce que la hipótesis Santorini-Atlantis no tiene base científica y que toda la historia completa de la Atlántida puede, en definitiva, resultar ser nada más que una imagen creada por Platón para probar algún punto de vista filosófico. A partir de esta conclusión, resulta interesante atender al uso del mito de la Atlántida que hace el mismo Platón -ya que una respuesta a esta inquietud nos aproxima a la ambivalencia de los símbolos y a la multiplicidad de significados que encierran los relatos mitológicos. ${ }^{8}$

Volviendo al mito mapuche del origen, una reflexión sobre el sacrificio de un niño mapuche, José Painecur, a raíz del megasismo y maremoto de 1960 en el sur de Chile, muestra la ambivalencia que tiene el símbolo de la serpiente para la comunidad mapuche, y cómo es posible

del colapso de la Creta Minoica, un tiempo suficientemente para descartar causa y efecto (Vitaliano, 2007).

8 En varias de las más importantes obras del período tardío de Platón, el uso del mito de la Atlántida del diálogo Critias, y de otros mitos análogos, marchan paralelo a un relato cosmológico probable del mundo del devenir (Timeo), al proyecto de un estado político ideal (República), a una particular concepción cíclica de la historia (Político), y a una reflexión historiográfica acerca de las causas del desarrollo y desmoronamiento de los principales sistemas políticos de su tiempo (Leyes). Entre los intentos de interpretación de los mitos platónicos, Görgemanns, 2004, pp.66-67, destaca: (i) su rol como "complementación necesaria para suplir carencias de la razón"; (ii) su función éticoexhortativa con finalidad moral; (iii) un significado "similar al de la revelación de la verdad", propio de tendencias religioso-mistéricas de su tiempo. 
la interpretación múltiple de un evento desde distintas ópticas culturales. Leiva (2013) presenta un muy completo análisis del sacrificio asociado al sismo de 1960 desde la perspectiva de la prensa y el sistema judicial chileno, que lo califica como un delito criminal; desde las ciencias sociales, que lo juzga como un acto simbólico-ritual ligado al mito del origen; y desde la propia comunidad mapuche, que lo considera como un ejercicio de derecho propio, basado en principios de equilibrio y reciprocidad con la naturaleza, al término de un ciclo de deterioro cultural a causa de la colonización por parte de la sociedad hispánica. La diferencia de percepción de acontecimientos que tienen culturas diferentes también es ilustrada por Hernández (2009), en relación a un juicio contra "brujos" llevado a cabo por el Juzgado de Ancud, en Chiloé, entre 1880-1881. Pese a que la práctica de brujería, adjudicada a un grupo de demandados de ascendencia huilliche, es juzgada como expresión de superstición e ignorancia, el mismo archivo judicial da cuenta de una organización muy desarrollada, capaz de ejercer un poder paralelo a la ley tradicional, y que además creía afirmar la existencia de lo que para nosotros son simples elementos mitológicos (Hernández, 2009, p. 39). De acuerdo a Ruiz (1995) ${ }^{9}$, la Recta Provincia, la sociedad de brujos de Chiloé, como asimismo otras asociaciones mistéricas, comparten la misma tendencia:

Ser modelos reducidos de sociedad, aunque extensibles de manera mágica, asi como la de pretender ocupar el mundo entero. Sólo que este dominio del mundo es poético y no se hace efectivo sino con medios sacramentales, nunca militares. Así es como cada aldea de Chiloé, en donde reside la autoridad de los brujos, posee una correspondencia mágica con otros lugares del mundo (1995, p. 115).

Los casos examinados nos llevan a concluir que no se puede pretender explicar el mito de acuerdo a los modos racionalmente ajustados al saber occidental, sin tomar en consideración el

9 Ruiz (1995, p. 114): La Recta Provincia, sociedad de brujos del sur de Chile, en Chiloé, toma prestadas sus estructuras a la Inquisición y al Imperio Español, las que combina con las reglas y ritos de paso de los universo simbólico de donde emerge, ni el sentido y significado que la comunidad misma confiere a la narración. Finalmente, cabe la pregunta ¿Por qué la imagen de la serpiente adquiere tal relevancia, no solamente en el mito del origen del pueblo mapuche sino que también, y desde tiempos inmemoriales, en el universo simbólico de numerosas y distintas culturas? Rosete, siguiendo a Warburg, estima que, para la etnia Pueblo de Norteamérica, la serpiente es:

Encarnación del mysterium del mundo, como numen terrenal que habita en las profundidades e inesperadamente emerge, la serpiente puede generar las mayores calamidades para el hombre, pero justamente por eso tiene la capacidad de salvarlo: la serpiente mata pero también da vida, da lluvia, y la única posibilidad de vida y de sentido para los Pueblo es estableciendo una conexión espiritual con el numen, a pesar de ser un peligro latente (Rosete, 2006, p. 277).

\section{UNA IMAGEN DEL MITO DEL ORIGEN: LA CULEBRA DE AGUA O FILOKO}

En el origen de los tiempos, el río Klamath corría por un lado hacia arriba, por el otro hacia abajo, pero el creador decidió que las aguas del río descenderían y que los salmones remontarían el río (Lévi-Strauss, 1968 , p. 43) $)^{10}$

Las "lampreas" (Clase Cephalaspidomorphi) y las "mixinas" (Clase Myxini) son los únicos grupos sobrevivientes de una rama extraordinariamente arcaica y diversa de peces, la que ha recorrido y serpenteado por millones de años las aguas dulces y saladas del planeta y ha logrado reptar hasta el horizonte actual-desde las profundas oscuridades del tiempo evolutivo en el que se han ido extinguiendo la mayoría de las clases emparentadas. Se trata de la primitiva estirpe de los Vertebrados "Agnados" (Superclase Agnatha), un grupo parafilético con alrededor de 100 especies vivientes que comparten

médicos gallegos, los meigos, así como a diversos otros organigramas de origen republicano.

10 Mito indígena de Norteamérica destacado por Erikson y citado por Lévi-Strauss (1968). 
el rasgo común de no poseer mandíbulas y exhiben distribución anfitropical, en aguas relativamente frías, la mayoría del Hemisferio Norte. Además de la carencia de un aparato mandibular, la notocorda o cuerda dorsal persiste a lo largo de la vida del animal y tienen porciones de un esqueleto cartilaginoso. Los Agnados constituyen el grupo más antiguo y primitivo de todos los Vertebrados y su origen se remonta al período Ordovícico de la Era Paleozoica, hace alrededor de 480 Mill años atrás; fueron muy abundantes hasta su práctica desaparición en el período Devónico, alrededor de 370 Mill años atrás.

Dentro del grupo de las lampreas supervivientes (Cephalaspidomorphi -Orden Petromyzontiformes), los estudios biogeográficos, anatómicos y taxonómicos (Potter \& Strahan, 1968; Potter et al. 2015) indican que sus 10 géneros y 41 especies vivientes se pueden incluir en tres familias distintas: (i) Geotriidae, familia monofilética y monogenérica que incluye solamente una especie monotípica, Geotria australis, de distribución en aguas continentales de Australia, Tasmania, Nueva Zelanda, Chile y Argentina en Sudamérica, Islas Malvinas y Georgias del Sur; (ii) Mordaciidae, familia también monogenérica y cuyo único género Mordacia incluye tres especies: $M$. lapicida, endémica de Chile y $M$. mordax y $M$. praecox, endémicas de Australia y Tasmania; (iii) Los restantes ocho géneros y 37 especies de lampreas habitan en el Hemisferio Norte y se incluyen todos en la Familia monofilética Petromyzontidae. Los estudios moleculares (Lang et al. 2009; Potter et al. 2015) destacan a las dos familias del Hemisferio Sur como las basales en la filogenia del grupo entero de las lampreas Petromyzontiformes. Estos antecedentes subrayan el extraordinario interés evolutivo-biogeográfico de las especies de lampreas de distribución exclusiva en el Hemisferio Sur, tanto en referencia al desarrollo y diversificación del grupo viviente, el Orden Petromyzontiformes, como asimismo su arcaica vinculación al antiguo hipercontinente de Gondwana, que reunía los actuales continentes de África, India, Australia, Tasmania, Nueva Zelanda, Antártica y Sudamérica. Numerosos linajes de plantas y animales de los ecosistemas de bosques subtropicales y templadolluviosos del Cono Sur de Sudamérica exhiben este mismo patrón de disyunción gondwánica, como ya ha sido destacado por numerosos autores (cfr. Villagrán \& Hinojosa, 2005).

Geotria australis y Mordacia lapicida se reproducen en agua dulce $y$, luego de experimentar una complicada metamorfosis migran al mar, y perduran como especies parasíticas y hematófagas en su fase adulta y marina; en contraste, las larvas tienen forma de gusano, son micrófagas, ciegas, sin dientes y permanecen varios años enterradas en el fango de ríos y corrientes. En la fase adulta desarrollan ojos funcionales y un disco succionador armado de dientes. En lo que se refiere a la distribución de las dos especies chilenas, sobre la base de antecedentes documentados en la literatura y registros propios, Neira (1984) define tres núcleos distribucionales discontinuos para Geotria chilensis: (i) Chile central, desde los alrededores de Santiago hasta el Maule; (ii) Chile central-sur, desde San Carlos hasta la desembocadura del río Maullín; (iii) Chile Austral, Aysén y Tierra del Fuego. De acuerdo al actual diagnóstico del estado de conservación, la especie ya habría desaparecido en Chile central y Magallanes; su distribución se restringiría entonces a nueve cuencas entre las regiones de Bíobío y Aysén, entre $36^{\circ}$ y $45^{\circ}$ S. Mordacia lapicida es endémica de Chile y comparte en gran medida el área de distribución chilena de G. australis y, en varias cuencas, ambas especies son simpátricas.

En la región de la Araucanía, en la cuenca hidrográfica del rio Toltén, se realiza una de las escasas faenas tradicionales de pesca de Geotria australis, la "lamprea de bolsa" o "anguila blanca". Se trata de la comunidad mapuche de Gorbea, situada en el entorno del rio Donguil, cuya actividad es relatada por Reyes y colaboradores (2014), de acuerdo entrevistas de terreno realizadas a los pescadores:

Anualmente en La Poza se reúnen miles de ejemplares de $G$. australis que ven interrumpida su migración por el río Dónguil debido a la presencia de El Salto. Sin embargo, las lampreas logran continuar su migración gracias a que salen hacia tierra por una planicie o terraza fluvial y transitan por un sendero de baja pendiente que accede a la parte superior (aguas arriba) de El Salto. Cuando esta situación ocurre, generalmente en septiembre u octubre, 
dependiendo de las condiciones ambientales, los mapuches las capturan con el objetivo de alimentarse de ellas. La fecha exacta (mes y día) de la salida de las lampreas depende fundamentalmente de la lluvia. Es una condición sine qua non que llueva lo suficiente (uno o más días) para que aumente el nivel de agua de La Poza en cerca de $15 \mathrm{~cm}$, hasta quedar al mismo nivel que la terraza aledaña, lo cual permite a las lampreas alcanzarla (2014, p. 6).

Aparentemente, se vincula la forma de vida alargada del animal, su reptar por el terreno húmedo, sus vaivenes ondulantes, con la serpiente del mito originario, la cual también sube desde el mar. Esta analogía se expresaría en las designaciones en mapudungun del pez, a saber, filokomo o filoko, "serpiente de agua", "serpiente de lugares aguanosos" (filo, vilu "serpiente"; ko "agua"). De acuerdo a Reyes y colaboradores (2014), las características morfológicas del animal, por un lado, y narrativas orales, por otro, llevan a la comunidad a una representación del filoko como el "espíritu del agua" en forma de culebra. Pero no se trata solamente de la forma de vida del animal adulto, también son centrales las dos fases del ciclo de vida, gusano y culebra; la conducta de las larvas, ciegas y enterradas en el fango del fondo de los ríos, y su posterior descenso al mar; el remontarse a contracorriente de la fase adulta, desde el mar hacia los ríos, para reproducirse; la eventual movilidad fuera del agua para sortear obstáculos, aprovechando la crecida del río con las lluvias. En definitiva, la expresión irrefutable de su dominio es su capacidad de ascender y descender las aguas, vivir algún tiempo en el fango, conquistar también la tierra. Este comportamiento es el que le confiere resonancia con el mito del origen, lo que la constituye como la representación física de la mítica serpiente kaikai del relato del origen: la que manda las aguas. Las oposiciones del mito del origen siguen presentes: el arriba y el abajo; el agua y la tierra; el este y el oeste; el sol y la luna, etc. El animal es personificado como espíritu o nguen del agua, "señor del agua", nguen-ko ${ }^{11}$, lo que potencia su importancia como referente simbólico en la comunidad mapuche de Gorbea.
Es interesante destacar que la integración del comportamiento del animal con el conjunto de las condiciones del entorno es considerada por los pescadores, ya que este todo proporciona las señales para el éxito de la actividad de pesca. Así, la velocidad de la corriente del río, las condiciones del suelo, los montos de las lluvias, el comportamiento de las aves, de la luz, de las fases de luna, etc. Tampoco es trivial el emplazamiento de la actividad, junto a una caída de agua, si se considera que estos sitios han sido siempre muy venerados por las comunidades mapuche, en sus ceremonias de petición de lluvias, como relata Guevara:

En ciertos parajes en que las aguas caían desde una altura o se deslizaban por sus cauces con mucha rapidez, el ruido de la caída o de la corriente se trasmitía con más intensidad en días de especial estado atmosférico. Espresaban este sonido, augurio de lluvia, con la palabra llanllahuen, i el sitio en que lo oían les inspiraba un supersticioso temor. Ahi se reunian, pues, para celebrar sus ngillatun de lluvia (1908, p. 310).

Los datos, obtenidos en la entrevista realizada por Reyes y colaboradores (2014), entregan una imagen sobre la relación de los animales con las condiciones naturales que dan forma y vida a una relación simbólica. En lo referente a las condiciones de luz, lluvias y suelo, los autores citan los comentarios de los pescadores entrevistados: Para que la recolección se efectúe, primero debe haber luna llena, y luego debe llover por al menos $48 \mathrm{~h}$ para que el suelo se moje y aumente el nivel de agua de La Poza (Ibid., p. 6). El comportamiento de las aves anuncia la llegada de las lampreas: $L a$ señal que esa noche saldrán las lampreas está en la copa de los arboles aledaños, los que se llenan de cuervos (Ibid., p. 6). En el sabor del agua las lampreas sentirían la señal de la tierra cercana: cuando abandonan el rio las lampreas ya le sintieron el sabor amargo al agua (Ibid., p. 7). Las lampreas percibirían la amenaza del hombre: se comunican unas a otras que están en peligro (Ibid., p. 7). La pesca se realiza de noche y sin luz

11 De acuerdo a Grebe (1998, p. 63), ngen-trayenko, "dueño del agua de la vertiente" 
artificial porque las lampreas regresarían al río si alguno de los pescadores prende una linterna o foco. La única luz favorable para ellas sería la de la luna, que necesariamente debe encontrarse en fase llena: la luna llena actuaría como faro para las lampreas al salir del río (Ibid., p. 7).

Por otro lado, también las actividades tradicionales de subsistencia, como la pesca de la lamprea, están traspasadas por relatos míticos transmitidos oralmente, los cuales contextualizan una mirada y un comportamiento propio de la comunidad frente a la naturaleza. La lamprea para esta comunidad representa un importante recurso natural de alimentación, con reglas y funciones para sus habitantes, y esta necesidad instaura una actividad cultural que se articula a un mito acerca de su origen ya que, como afirma Eliade: No se puede cumplir un ritual si no se conoce el "origen", es decir, el mito que cuenta cómo ha sido efectuado la primera vez (1963, p. 23). Un buen ejemplo de ello lo constituye una leyenda citada por Reyes y colaboradores (2014) y que se refiere al origen mítico de la actividad de pesca de lampreas:

Hace muchos años atrás durante una mañana de verano en la cual tres pequeñas hermanas se bañaban en él río Dónguil, una de ellas nadó hasta una gran piedra ubicada en la mitad de éste. [...] luego se hundió lentamente en el agua. [...] Durante una fría mañana del otoño siguiente, la niña desaparecida apareció de la nada frente a su madre y le dijo: "este invierno va a ser muy crudo y las cosechas no van a alcanzar para todos, pero durante una noche van a salir del río unas culebras con siete oídos a cada lado de la cabeza, espérenlas y recojan el máximo, guárdenlas para comer " [...] vivía en un lugar muy frío y oscuro, y por eso no podía ver el fuego, tampoco las culebras con siete oídos, por lo tanto los que fueran a recogerlas al río no deberían usar fuego para iluminarlas. [...] Como la niña dijo, ese año salieron las lampreas y la gente de la aldea las capturó, las secó y las ahumó, de esa manera todos tuvieron alimento para sobrevivir ese año. Desde ese entonces la gente de El Salto comenzó a comer lampreas (2014, p. 10).

Nuevas oposiciones recorren este relato, como noche y día; luz y oscuridad; frio y calor; escasez y abundancia; vida y muerte. El relato integra rasgos del mito del origen, en permanente unión fundacional con otros mitos relacionados. Como afirma Lévi-Strauss: Siguiendo paso a paso el desenvolvimiento de un mito se lleva a otros muchos que lo aclaran y permiten percibir los nexos orgánicos que ligan a todos (1968, p. 3). Así, esta narración se vincula con otras leyendas ampliamente extendidas, como una del Lago Budi, donde aparece el rapto de una niña araucana robada por el Shumpal o Sompallhue, ser mitológico, genio y dueño de los lagos y mares, en cuyas profundidades habita (Koessler, 1997; Guevara, 1908). En una versión muy parecida del Shumpal, citada por Foerster (1993, pp. 169170), los familiares de la niña reciben en pago muchos y lindos pescados. En Chiloé este espíritu, también llamado Pincoy o Tritón, se transforma en un anciano que visita a la gente $y$, dependiendo del trato que reciba, trae pesca abundante o escasez. Este espíritu del agua, ngen-ko, descrito como un remolino o como una gran ola, evoca a los antepasados mapuche transformados en peces durante la catástrofe que narra el mito del origen, que también raptaban muchachas, como asimismo a la serpiente caicai, de acuerdo a Grebe, ngenlafkén, "dueña del agua del mar" (1998, p. 63). La importancia de los mitos del origen y el rasgo ambivalente del símbolo de la serpiente quedan así, otra vez, claramente manifiestos.

\section{UNA REFLEXIÓN EN TORNO A LA REPRESENTACIÓN MAPUCHE DE LA NATURALEZA.}

El Rewe. Árbol cósmico, que permite la conexión del mundo natural hacia el mundo sobrenatural (Ñanculef, 2004b, p. 44).

Los mapuches antiguos tenían buenos conocimientos de todas las cosas existentes: sabian nombrar las estrellas que brillan en la bóveda celeste; los pájaros y aves que vuelan en el aire; los animales que andan sobre la tierra y las diversas clases de insectos; hasta los peces que nadan en los ríos y en el mar. Además conocían los árboles y plantas; hasta las piedras tenian su nombre (Coña, 1930, p. 78). 
La singularidad del conocimiento de la naturaleza por parte del pueblo mapuche reside en la articulación de cada elemento del entorno -sea piedra, tierra, agua, planta, animal, territorio, etc.en un sistema de relaciones que exhibe la marca de una cosmovisión integradora del universo, basada en ideas y principios que tienen un significado propio para el grupo. El orden cósmico se fundamenta en el culto a los antepasados, en una noción cíclica y reversible del tiempo, en una concepción del espacio gobernada por su orientación hacia el Este, y en una organización regida a partir de la convergencia de cuatro principios o "energías": kuze "tierra", fücha "agua", ülcha "aire" y weche "fuego" (Guevara, 1908; Nanculef, 2004a; Grebe, 1998). El rewe constituye la representación icónica de la construcción simbólica del cosmos mapuche [...] el cultrún mapuche (timbal chamánico) representa a la tierra mapuche (Grebe, 1998, p. 62).

En la cosmovisión mapuche aún no existe el grado de distanciamiento que lleva a la dualidad sujeto-objeto, a la dicotomía entre el concepto formal de naturaleza y la sociedad, escisiones que signan la concepción moderna de la ciencia occidental. El hombre no está separado sino inmerso sensualmente en la naturaleza material y este mayor compromiso con ella se expresa en sus representaciones simbólicas, aún cercanas al detalle sensible, palpable y concreto. De acuerdo a Guevara: El araucano primitivo extendió al universo entero la multiplicidad de espíritus semejantes al que residía en él. Unos tenían su morada en los animales, en las plantas $i$ objetos inanimados, o bien representaban los fenómenos de la naturaleza (1908, p. 285-286). La creencia en los ngen o "dueños" de la naturaleza se desprende de este universo simbólico mapuche, como el ngen-ko, amo del agua, ejemplificado por el caso de la lamprea ya comentado. Tampoco se manifiesta aún la diferencia entre seres vivos y lo que la ciencia moderna considera materia inanimada. Todos los entes y procesos naturales son concebidos a imagen de la percepción humana y relacionados en torno a su significado para el hombre. Este animismo o "personificación" de la naturaleza, en palabras de Elías (1984), se expresa así: todo cuanto acontece tiene una voluntad $y$ unos fines y actúa como los hombres, ya se trate del sol, un árbol una roca o inclusive una barca (1984, p. 35).

Este estudio se focaliza particularmente en el rol central que juega la imagen de la serpiente del mito del origen, como asimismo otras representaciones simbólicas de elementos naturales relacionados con ella, y que comparten alguna característica común: sea alguna forma alargada y rastrera; sea una movilidad serpenteante; sea una conducta particular; sea el daño que causan; sea el lugar que habitan, etc. Estos elementos pueden encontrarse en linajes humanos o animales - reptiles, peces $\mathrm{u}$ otros grupos de invertebrados- como asimismo en plantas, configuraciones geográficas o estructuras geomorfológicas y geológicas. Varios autores ya han destacado la relevancia que adquieren algunas imágenes de animales en el universo de significaciones de la cultura mapuche, por ejemplo, en relación con actividades de subsistencia, como se ha documentado en el capítulo anterior; en la denominación y categorización del entorno geográfico (Ramírez, 1995); en la unificación totémica de los linajes (Möesbach, 1963; Kuschel et al. 1997); en la nomenclatura y etnoclasificación de la biota (Coña, 1930; Moesbach, 1992; Villagrán et al. 1999; Villagrán 1998); en la simbolización de la propia organización social y ritual (Grebe, 1998; Guevara, 1908; Plath, 1994, 1995; Koessler, 1997).

Dos nombres comunes de animales adquieren especial relevancia en la construcción, descripción y denominación del entorno natural: el de la "serpiente", filu, vilo o vilu y el del "gusano", piru; con ellos se construye una diversidad de nombres propios de distintos componentes de la naturaleza. Entre los topónimos, Ramírez (1995) cita, por ejemplo, designaciones topográficas como Vilupulli (pülli=suelo); nominaciones geomorfológicas, como la Cordillera de Pirulil (lil=peñasco); también territorios pertenecientes a linajes, como Piruquina (künga=estirpe); Filulahuén (planta medicinal en el territorio de Filú); Vilo (antropónimo usado como topónimo); de acuerdo a Guevara, cada localidad estaba dotada de espíritu como la espresión de poder $e$ influencias sobrenaturales, determinado por alguna particularidad de la comarca, de la fauna o flora. Jeneralmente era un animal. La veneración de este fetiche constituía el culto 
del totem, que daba nombre a las comarcas i a los individuos (1908, p. 286). Algunos ejemplos de patronímicos relacionados a la serpiente y al gusano, son los apellidos citados por Kuschel et al. (1997): Piruanca "cuerpo de gusano", Pirul "gusano de roca", Filcún o Filún "ser serpiente", Filipai "vino la culebra", Filtuñanco "serpienteaguilucho", Filumilla "serpiente dorada", Filura "culebra florida", Curivil "culebra negra", Cafil "una culebra más", Caimapo "tierra de serpientes", Caifil "seis serpientes", Caihuan "serpiente de la tarde".

Las designaciones mapuche de clases de animales con figuras analogadas a la serpiente y al gusano no son concordantes con los grupos taxonómicos de la ciencia zoológica, sino que reúnen animales pertenecientes a linajes evolutivos muy distintos, pero que comparten una forma de vida y una conducta similar. Como se mencionara antes, peces como las "lampreas" (Geotria australis y Mordacia lapicida, Agnados), son llamadas komofilu o filoko (serpiente de agua). Sin embargo, las palabras vilu y piru son usadas para nombrar principalmente a diversos linajes de Invertebrados (Phyla). Entre los MoluscosGastrópodos, Invertebrados de cuerpo blando, varias clases de caracoles terrestres desnudos son llamados llomllómpiru (llomllóm, caracol). En el gran grupo de los Artrópodos, Invertebrados de cuerpo articulado, hay nombres de arácnidos, miriápodos e insectos que comparten las palabras en común que se comentan. Entre los Insectos, la larva de la "polilla de la ropa" es llamada müñupiru (Tineola bisselliella, Familia Tineoidea). nombre evoca a un gusano, la larva saliendo de su estuche entre las hebras de tejido: Hay una clase chica muy odiosa de esos bichos, que corroe todas las prendas de vestir, mëñupiru (Coña, 1930, p. 116). Entre los Arácnidos, el "escorpión o alacrán” (Centruroides margaritatus, Familia Buthidae), cuyo nombre mapuche es kaikai piru, también trewanke. Coña se refiere al animal así: Además hay ese repugnante alacrán o escorpión. Sus patas están provistas de unas

12 El nombre Hemiscolopendra chilensis, bajo el cual la especie ha sido citada en la literatura etnográfica ha pasado a sinonimia.

13 La especie ha sido citada en la literatura etnográfica como Gordius chilensis. De acuerdo a De Villalobos et al. pinzas, con las cuales agarra cualquier insecto. En su abdomen tiene un aguijón, con que perfora los bichos apresados (Ibid., p. 117). Entre los Miriápodos, el "ciempiés" más grande Chile, Akymnopellis chilensis ${ }^{12}$, (Chilópoda, Familia Scolopendridae) es llamado, wiyufilu. Es un gusano de hasta $12 \mathrm{~cm}$ de largo, habitante de la hojarasca húmeda de zonas boscosas, desde Copiapó a Torres del Payne; suele pasar largo tiempo bajo tierra, tiene un bello color verde petróleo y es carnívoro predador, con el primer par de patas modificado como aguijón inoculador de veneno. Dice Coña: Otro bicho se asemeja algo a una culebrita, pero tiene muchísimas patas, se llama wiyufilu (Ibid., p. 117). Entre los primitivos linajes de Invertebrados acelomados figuran dos ejemplos: entre los Platelmintos, el endoparásito "tenia o lombriz solitaria" (Taenia solium, Familia Taenioideae) es llamada chapüd piru (chapüd, pegado, que se pega). Dice Coña en referencia a los gusanos: Algunos viven dentro de la tierra; otros se crían hasta en los intestinos de la gente. A esos pertenece chapëd-piru (Ibid., p. 121). Entre los gusanos nematoídeos, el "pelo de agua" o "pelo de caballo" (Gordius austrinus, Nematomorpha) ${ }^{13}$, un delgadísimo y largo gusano filiforme del grosor de un cabello, -que se retuerce en los charcos y parasita invertebrados en sus estadios larvales-, es llamado iwayfilu (culebra de pelo o culebra dragón).

En la nomenclatura botánica, el término filu o vilu, como asimismo el nombre de la serpiente mítica, caicai, es usado para consignar nombres propios de plantas pertenecientes a familias muy distantes entre sí, dentro del gran grupo de las Plantas con Flores -Angiospermas-, pero que comparten hábitats cenagosos o semi-inundados, o bien órganos rastreros o subterráneos -como tubérculos, estolones y rizomas- formas de crecimiento, hojas, flores, frutos, semillas $\mathrm{y} / \mathrm{o}$ condiciones de vida relacionadas con la culebra. Así, los nombres de tres pequeñas plantas rizomatosas: una pequeña hierba de hondonadas sombrías y húmedas del bosque se llama

(2005), este taxón es inválido porque ha sido mal descrito -sobre la base de escaso material de referencia que se ha perdido- y corresponde, probablemente, a la nueva especie que ellos han estudiado y descrito como Gordius austrinus, con amplia distribución en Chile. 
mellaufilu, milahufilu o millahuilo, "caracolculebra" (Pilea elliptica, Familia Urticáceas). En hábitats de aguas estancadas crece la centella, Centella asiatica (Familia Apiáceas), una reputada hierba medicinal (lahuén), con largos estolones rastreros tendidos horizontalmente sobre los suelos semi-anegados; es llamada pihuichén-lahuén ${ }^{14}$, "hierba del culebrón" (piwichen, animal imaginario como murciélagovampiro). Igualmente, en hábitats pantanosos de turberas, vegas y mallines crece un pequeño junco, con rizomas estoloníferos, y rosetas de hojas alargadas y espinosas, Juncus cyperoides (Familia Juncáceas) llamado ühuafilu, "maíz de la culebra" (üwa, maíz). Los órganos subterráneos de las plantas también evocan a la serpiente; así, por sus gruesas y alargadas raíces tuberosas, algunas orquídeas son llamadas ühuafilu, "choclo de la culebra", como Chloraea speciosa, Familia Orchidáceas. Asimismo, por sus tubérculos subterráneos, la "papa" (Solanum tuberosum, Familia Solanáceas), conocida como poñi en el mundo mapuche, a veces es llamada filu-cachu "mata de la culebra". Por la forma ovoide de las flores, los "capachitos o zapatitos", traupitraupi o trapitol, las numerosas especies del género Calceolaria, Familia Calceolariáceas, son llamadas kuramfilu "huevos de serpiente" (kuram, huevo). Tienen una corola característica, generalmente amarilla oro, ovoide, hueca e inflada como una bolsita o zapatito, conformada por dos lóbulos que se acercan entre sí, a veces con manchas o rayas rojas, de ahí el otro nombre topatopa, tropatropa que también tienen (tropa, mancha). Las alargadas y flexibles hojas espinosas de la mata de ñuyu, cuyo fruto comestible es llamado "chupón", son denominadas cai "serpiente" (Greigia sphacelata, Familia Bromeliáceas). Comenta Moesbach: Las hojas largas y espinudas como serpientes -caise relacionan en la mitología araucana con cierto culebrón fabuloso, enemigo del género humano, denominado Cai-Cai (1992, p. 66). Quizás la voluminosa roseta de hojas alargadas y sésiles, que se van doblando en las puntas hacia la

14 Es interesante la construcción de nombres con la palabra "remedio", lawen, asociada a imágenes serpentoides negativas, porque vincula los conceptos de transgresión y restauración del orden natural por medio de "el espíritu de las planta medicinales, ngen-lawén” (Grebe, 1998, p. 63). periferia de la mata, parezca un nido de culebras. Entre los Helechos, por sus largos, gruesos y oscuros rizomas que serpentean sobre los troncos, el helecho epífito Polypodium feuillei es llamado filu-lahuén "hierba o remedio de la culebra", o fillcuñ-mamëll "madera del lagarto", también kalahuala.

Además de las serpientes del mito del origen, caicaifilu y trentrenfilu, numerosas leyendas tradicionales cuentan acerca de animales mitológicos, generalmente habitantes del agua, relacionados con la culebra, como ngürüfilu ${ }^{15}$ (culebra - zorro, acuático), kurufilu (culebra negra de agua), ñarkifilu (gato con cabeza de culebra, marino), cuchivilo (cerdoculebra), trillkefilu o hueke o huekú (cueros de agua, cueros vivos con uñas), chinifilu (culebracanasto). Comenta Coña: Se cree también en la existencia de un serpentón o culebrón, -iwaifilu, iwai-piuchén- y un dragón kaikaifilu, animales fabulosos que nadie jamás ha visto (1930, p. 118). Relata Guevara: Transformado en algún animal mítico o en pájaro, el espíritu del brujo atraviesa el espacio y llega a esos subterráneos cuya entrada defiende un monstruo, que es muchas veces una serpiente mítica (ihuaivilu) (1908, p. 256). Febrès nombra por primera vez una serpiente "que vuela" y le llama pihuychen (1765, p. 399). Augusta describe al piwichen ${ }^{16}$ : Tiene el cuerpo de forma cilíndrica alargada, como la culebra. Con el tiempo le crecen alas, y vuela, pero carece de plumas. Chupa la sangre de la gente y de animales [...] su silbido es anuncio de muerte (1916, p. 185).

El origen de algunos nombres de plantas que comparten la raíz vilu aparece relatado en leyendas tradicionales mapuches, recopiladas por Koessler (1997) en Neuquén, Argentina. Estos relatos nuevamente ilustran la necesidad de retrotraerse al origen sobrenatural o "creación" de la existencia de algo para dominarlo, y también las frecuentes transformaciones que experimentan mutuamente los distintos componentes del universo natural. Por ejemplo, para el nombre kuram vilu de las flores de

15 En la toponimia, Ngürüfilu, Nirivilo es una localidad ubicada en la comuna de San Javier, en la Región de Maule.

16 La grafía cambia en distintos autores: Havestadt "pihuichen", Molina y Latcham "piguchén", Guevara "piuchén" 
las especies de Calceolaria, una primera leyenda ${ }^{17}$ cuenta de un monstruo mitad hombre y mitad serpiente que los indios intentan matar, pero que logra escapar. En el sitio donde estaba su gruta el suelo estaba cubierto de flores amarillas que los indios llaman aún kuram filu (huevos de culebra (Ibid., p. 29). Sobre el mismo tema, una segunda leyenda ${ }^{18}$ narra cómo una doncella se transforma en una gigantesca serpiente negra del agua, kurufilu, que convierte en bloque de piedra a un cruel cazador de serpientes: en el mismo sitio se pasean ahora culebras y viboras y florece la planta que llaman traupitol y también topa-topa, cuyas flores amarillas en forma de bota denominan también kuram-filu (huevos de serpientes) (Ibid., p. 63). Asimismo, el nombre del helecho kalahuala o filu-lahuén (Polypodium feuillei, Asplenium trilobum) es tratado en otro relato ${ }^{19}$ acerca de un matador de víboras que fue víctima de "la maldición de los reptiles" vía seducción por una bella muchacha llamada Kalahuala que se transforma en una enorme serpiente que lo apresa $y$ es destrozado al mismo tiempo por un millar de culebras y lagartos venenosos de vientre azul y verde (Ibid., p. 79). Del mismo modo, el origen del colibrí o pinda, un ave de mal agüero para los mapuches, se cuenta ${ }^{20}$ que se remonta a los crímenes de una mujer llamada Paynefilu "víbora azul" que fue quemada por el sol y de cuyos restos brotó un ser vivo, un diminuto pájaro, el colibrí, el pinda o pinsha, que nunca ha de morir de muerte natural porque proviene de un corazón malvado (Ibid., p. 96).

De particular interés es un mito recogido por Ramírez (1995), y también mencionado por Augusta (1916), que narra acerca de una culebra enorme llamada Piruquina:

Es una culebra gigantesca que requiere más de 25 años para desarrollarse completamente, y una vez enterado este lapso, emerge desde las profundidades de la tierra produciendo un fuerte temblor. En primer lugar aparece su cabeza, luego abre sus enormes ojos, y si alguna persona se

Op.cit. p. 29: "El monstruo de la bota de oro", Koessler, 1997, pp.26-29.

18 Op.cit. p. 63: "La Doncella Serpiente", Koessler, 1997, pp. 61-63. encuentra al alcance de aquellos, la persona morirá en el acto. En cuanto la Piruquina ha logrado salir a la superficie de la tierra, las escamas de su cuerpo cambian desde un rojo intenso a otro más oscuro, de tono terroso. Finalmente se desintegra, y en el lugar donde se produjo su aparición queda como rastro de su presencia un conjunto de gusanos oscuros (1995, p. 130).

Esta leyenda es interesante por su manifiesta relación con eventos geológicos de vulcanismo, frecuentes en la región y en el país. Se trata de un relato estructurado que nos entrega una percepción subjetiva de acontecimientos naturales, pero que incluye los elementos que permiten su conexión con un proceso de erupción volcánica: así, la salida de la lava y cenizas desde el interior de la cámara magmática, como una gigantesca culebra; el paso del color rojo intenso de sus escamas a un color más terroso, una analogía con la salida de la lava incandescente y su posterior consolidación en contacto con el aire; así, los movimientos sísmicos asociados a la erupción; el peligro de muerte para quien está cerca y puede ver los ojos de la serpiente, la lava candente; las coladas de lava y lahares que escurren por las laderas, serpenteando como gusanos oscuros.

Como se mencionara antes, en un país afectado por intensas y frecuentes erupciones volcánicas, no es sorprendente la existencia de relatos simbólicos que incorporen la percepción de estos fenómenos. Guevara reseña que: Pillan era el espíritu del trueno, dueño de las nubes, de las lluvias, el viento, el rayo i las erupciones volcánicas (1908, p. 293). Por su gran poder se le reverenciaba más que otros espíritus. De acuerdo a Koessler (1997) el nombre de la culebra tutelar del mito del origen, Trentrén, quiere decir también "volcán", onomatopeya que imita el tronar dentro de la montaña. La polaridad ambivalente del símbolo de la serpiente queda expresada una vez más en todos estos relatos. También la indiferenciación entre animales, plantas o formaciones geológicas y el hombre, expresada en las frecuentes metamorfosis entre unos y otros.

19

Op.cit. p. 79: "Kalahuala, la Reina de las Perlas", Koessler, 1997, pp. 78-80.

20 Op..cit. p. 96: "Donde y como tuvieron origen los colibries", Koessler, 1997, pp. 93-96. 
HUELLAS EN TORNO A LA ETNOGRAFÍA DEL PIRU O "GUSANO”

La serpiente encarna también la polaridad del símbolo, la dinámica entre "agonía y la terapia», entre la lucha y la recuperación (Warburg, 1923). ${ }^{21}$

Para el pueblo mapuche, el origen de las enfermedades se vincula a la imagen de piru, "gusano", como agente transgresor que provoca desequilibrio y daño, tanto al cuerpo, como a la comunidad y a las siembras de los campos. A continuación, se examinan algunas relaciones, relatos y conceptos que, desde la visión mapuche, son consideradas como causales de enfermedad; se detallan como ejemplos los casos de la peste viruela y las enfermedades dentales. La indagación se centra en distintos aspectos étnicos enlazados con la mitología, historia y ciencia local relacionadas al vocablo piru y sus implicancias en el universo simbólico de la medicina mapuche.

Desde la remota antigüedad, el gusano ha sido vinculado a las enfermedades dentales. El agujero negro, característico de las caries, por mucho tiempo se ha considerado el escondite de un gusano, cuya presencia causa el dolor de muelas, $y$ al cual es necesario encontrar y extirpar ${ }^{22}$. En la historia de la odontología, el término español "neguijón", que designa al gusano causante de las enfermedades dentales, es mencionado por primera vez por Jerónimo Gómez de la Huerta, a principios del siglo XVII (Grifaldo, 2012). Como concepto tuvo vigencia hasta el siglo XVIII, cuando aparece en 1728 el trabajo del cirujano francés Pierre Fauchard, obra que lleva al olvido el concepto de neguijón y da paso a la odontología moderna, y al estudio de las caries con un nuevo paradigma. Sin embargo, el vocablo neguijón ya había cruzado antes los mares para llegar a América. Según Grifaldo, la mención de los gusanos de la caries,

21 De acuerdo a varios investigadores, la "conferencia" sobre el ritual de la serpiente entre los indios Pueblo, dictada por Warburg en 1923 en el Hospital Psiquiátrico Bellevue, Suiza, donde estaba internado- constituye un "acto ritual". La serpiente, el animal que más temor produce, encarna también la positividad del símbolo, la terapia y la curación.

22 Eliade (1963, p. 36), menciona un encantamiento asirio de destrucción del "Gusano" de los dolores de muelas, cuya "neguijon de dientes", aparece en la Nueva España en las primeras obras virreinales y se estima que esta creencia pasó de Andalucía a México (2012, p. 12).

En Chile, el término neguijón es introducido por el sacerdote jesuita Luis de Valdivia (1648), como traducción de la palabra en mapudungun pilolvoru- cuyo significado es "orificio en el hueso". Posteriormente, el Padre Andrés Febrès (1765), también misionero de la Orden Jesuita, define el concepto así: Pilolvoro, dientes, o muelas podridas, o huecas con gusano o el neguijón de ellas (1765, p. 663). De esta forma, la concepción occidental del gusano de los dientes o neguijón encuentra su paralelo en el ámbito de la odontología en la América precolombina. Si bien la descripción del término hecha por Febrès se refiere a un gusano de los dientes, el término en mapudungun citado no menciona la palabra "gusano", piru. Un vocablo más preciso para el agente de la caries pareciera ser piruforo, el término que las personas mapudungunhablantes consignan para el "gusano de los dientes". Fray Félix José de Augusta, misionero capuchino, registra ya el término piru foro y lo traduce como "muela carcomida" (Augusta, 1903, p. 280). Moesbach (1955) cita la palabra pichi piru: "pequeño gusano", nombre que dan los araucanos, guiados por una intuición bastante acertada a las bacterias causantes de las caries dental" (1955, p. 51).

Con posterioridad a las gramáticas de los jesuitas, se documentan tratamientos contra el neguijón basados en el uso de plantas medicinales. Así por ejemplo, el sacerdote jesuita Diego de Rosales (1877) dice: Las raices de Coro $^{23}$ son admirables para los pasmos y para lisiados, cocidas estas raices en vino, y mojar un paño y refregar el cuerpo por tiempo de nueve días; Mascándolas y refregándose las encías asfixian la dentadura y matan el neguijón (1877, p. 241).

Estos antecedentes etnográficos vinculados

eficacia terapéutica reside en un ritual que reactualiza el tiempo mítico del "origen" de la enfermedad.

23 "Coro" es probablemente Geranium corecore, de acuerdo a las descripciones de Gusinde (1916, p. 254): "Rorekore: Sus raices ason admirables para 1os pasmos y para lisiados... Refregandose las encinas affixan la dentadura y xnatan el negijon...Sus polvos templados puestos en 1os ojos quitan las cataratas y todas las pasiones de los frios". 
a la odontología permiten vislumbrar parte de un modelo de comprensión de las enfermedades, desde la perspectiva de la cultura mapuche. En este sentido, el vocablo piru se inserta en la dualidad salud-enfermedad, formando parte del sistema médico mapuche, como referencia simbólica al animal-agente. Otra enfermedad vinculada con el término piru es la peste viruela. Según Valdivia (1648), pirucutan, significa "peste o mortandad". Febrès también consigna el término piru cuthan - la peste de viruelas o cualquiera otra, y el dolor de muelas (1765, p. 597). De acuerdo Jiménez y Alioto (2007), cuando los jesuitas transcribieron el término cutan o cuthan como "enfermedad", empobrecieron la complejidad conceptual de la palabra.

El origen de la viruela se le atribuye al español o huinca y su etnografía ilustra una relación que permite indagar en las etnoclasificación de las enfermedades. En efecto, la viruela sirve de ejemplo de la separación entre enfermedades propias del mundo mapuche y epidemias introducidas por contacto con culturas externas. De acuerdo Jiménez y Alioto (2007), las enfermedades son hoy clasificadas por su origen y tratamiento en dos grandes categorías: wingka kutran o enfermedades que proceden de los wingka, o que se curan mediante la medicina occidental, y mapuche kutran, enfermedades endémicas. Estas últimas se dividen en tres categorías: re kutran, enfermedades naturales ajenas a cualquier intervención de un agente o fuerza intencional; wenu kutran, enfermedades originadas por una infracción a las normas sobrenaturales; y weda kutran, enfermedades provocadas por un agentehumano o fuerza sobrenatural maligna- con la intención de provocar un daño.

Entre las wingka kutran, la peste viruela es una de las más nefastas. La aparición de la viruela, con sus catastróficas consecuencias en la población mapuche, constituye una de las plagas más mortales introducidas por el mundo occidental. La relación entre el gusano y la enfermedad se expresa en la designación mapuche de la viruela, piru kutran (enfermedad del gusano). Según la información recopilada, piru, "gusano", y toda forma representativa que se desprende de su simbolismo, -ya sea, forma de gusano, tamaño, comportamiento, efectos dañinos como heridas con orificios, en piel, muelas, etc.-, personifica $y$ evidencia al agente que produce y propaga enfermedades, a través de los campos, personas, animales, etc. Góngora de Marmolejo se refiere así al inicio de la epidemia de viruela:

Francisco de Villagra, después que desembarco en la Serena, parescía venir pronosticando al reino mal agüero, y que de su venida les había de venir mucho mal, en general a todos, porque en desembarcando se infecciono el aire de tal manera, que dio en los indios una enfermedad de viruelas. Tan malas que murieron muchos de toda suerte, que fue una pestilencia muy dañosa, y por ella decían los indios de guerra, que Villagra no pudiendo sustentarse contra ellos, como hechicero había traido esa enfermedad para matarlos, de que cierto murieron muchos de los de guerra y de paz (1862, p. 94).

Sin embargo, el Padre Diego de Rosales desestima la procedencia occidental de esta terrible y mortal enfermedad, ya que no correspondería al carácter benigno de viruela visto en su tierra. Describe así las características de la peste observada, llamada piru, y la interpretación de su procedencia por parte de los indígenas:

Despedaza las carnes y haze unas grandes empollas que revientan en podre $y$ hediondez y están manando muchos días materia, sino quitan luego la vida. Los indios si se persuaden y están muy en ello que los Españoles les traen las pestes para acabarlos. Y a estas pestes de viruelas, que llaman Piru en su lengua, temen terriblemente, porque mueren sin remedio [...] Dicen los indios que en botijas encerradas llevan los Españoles estas viruelas de unas partes a otras y que donde quieren las abren para consumir a los indios (1877, p. 190).

Como se desprende de los comentarios de Góngora de Marmolejo y del Padre de Rosales, de acuerdo a los indígenas, el origen de la viruela estaría determinado por la introducción de artefactos de carácter mágico, que los españoles portaban ensacados en sus barcos y usaban 
intencionalmente como armas para propagar la muerte a través de los campos. Jiménez y Alioto (2007, p. 11) cuentan que esta creencia se inicia en 1611, durante el desembarco en la Serena de Juan Jara Quemada, recién designado gobernador de Chile, cuando se rompió una botija llena de lentejas y los porteadores indios difundieron la noticia que esas profusas semillas eran el origen y la fuente de propagación de la enfermedad. Así, la similitud de las manchas en la piel dejadas por las ampollas de la viruela, que aparentan un orificio dejado por un gusano, es relacionada con la forma de las semillas de lenteja traídas por los españoles en sus barcos, razón por la cual se le llama también "lentejuelas" a la enfermedad. Este acontecimiento nos permite comprender de mejor manera, la relación analógica que se establece entre la forma de una semilla, el agente gusano y el origen simbólico de una enfermedad; y también explica su denominación y la interpretación acerca de su rápida propagación. Los campos, la tierra -la proveedora de la vida y alimentoson perturbados y convertidos en propagadores de una enfermedad, de una alteración del orden natural. Hay una acción humana premeditada para hacer llegar los gusanos alteradores del orden. Esta interpretación se fundamenta en el concepto de transgresión del orden natural y social, el eje central de la noción de enfermedad de la medicina mapuche.

Los ritos y procedimientos de sanación utilizados por los chamanes mapuches, de acuerdo a la literatura, difieren según el caso, pero siempre tienen el sentido de reparar el orden alterado; nuevamente aparece acá el rasgo ambivalente del símbolo de la serpiente, la negatividad del agente piru, -un gusano o pequeña serpiente- y la positividad de la conexión espiritual del chaman con dicho agente mediante el acto ritual de sanación. En este contexto, es interesante destacar que, en conexión con la palabra piru, nuevamente acá se acude a la idea de gen o nguen -tal como fue mencionado en el caso de la lamprea. Esta relación

24 De acuerdo a Martín Alonqueo, citado por Foerster 1993, p. 66.

25 También de acuerdo a Martín Alonqueo, citado por Foerster 1993, p. 66.

26 De acuerdo a Guevara, los mapuches reconocen un Ente es consignada primeramente por Fèbres (1765) como genpiru: el dueño de la peste o gusanos, como si tuviera dominio sobre ellos (p. 597). El autor cita también para este mismo concepto el término gen phitù (p. 495) y menciona además una ceremonia llamada apùmpiru: junta para acabar el gusano (1765, p. 597). En este mismo tema Guevara afirma: Apenpiru (acabar los gusanos) se llamó una operación de carácter mágico para extirpar la plaga de gusanos en las siembras. El operador se llama ngenpiru (dueño o domador del gusano) (1908, p. 237).

Fèbres traduce gen como "ser, estar, haber, tener, y nacer" (1765, p. 494); Augusta transcribe la misma palabra como "ser", "dueño" (1903, p. 371). De acuerdo a Grebe, los ngen son seres espirituales animados, activos, con caracteres antropomorfos, zoomorfos o fitomorfos, que reciben órdenes de los dioses creadores mapuches (1998, p. 63). Al respecto, Nanculef señala: Los Gen son los dueños por excelencia de los elementos de la naturaleza, del agua, de los árboles, plantas, aguas, esteros, ríos (2004b, p. 35). Foester (1993) recopila distintas fuentes para esclarecer el significado de la palabra nguen o gen, en un intento de relacionar, explicar y comprender la conexión entre ngen, creación y naturaleza. Este autor menciona que ngen significaría "ser" y ngenén "ser dueño, autor, dominar, dirigir" (1993, p. 66) ${ }^{24}$. Al combinarse con la voz chen (formar gente) se plasmaría la expresión Ngenechen, palabra que sería un sustantivo que significa Ser supremo, la voluntad todopoderosa que domina, gobierna, dirige, guía, al ser inteligente o racional del mundo creado [...] Así ngen sirve como unión entre el Creador y lo creado; es un eslabón de la cadena de la "creación" (1993, p. 66) 25. Guevara (cfr. 2003) comenta que el culto preferente por los espíritus de los antepasados que tenían los primeros mapuches generó con el tiempo el de un poder supremo: de pillan ${ }^{26}$ o ngenechen o ngenemapu, señor del mundo y de los hombres (cfr. 2003, p. 84).

supremo llamado Pillan (de púlli o pilli, alma), que habitaba en la cordillera y volcanes, llamado también "Guenu pillan, el espíritu del cielo, Buta gen, el gran Ser, Tralcace, el Tonante (1908, p. 291). 


\section{CONCLUSIONES}

Uno de los propósitos principales de este trabajo era destacar los fundamentos culturales instaurados por el pueblo mapuche, en lo referente a la descripción de la naturaleza del territorio nacional. La singularidad de este aporte cultural se refleja tanto en la riqueza de denominaciones, modos de clasificación y usos del espacio geográfico y biótico, como asimismo en la articulación de estos aspectos a una cosmovisión integrada que considera el desarrollo equilibrado de la comunidad. En referencia a estos aspectos, nuestra indagación examina en particular la representación simbólica de ciertos animales vinculados al mito del origen $y$, por eso mismo, centrales dentro de la compleja trama de significados de la cosmovisión mapuche. Así, uno de los aportes del estudio fue destacar la relevancia de este contenido mítico en el conocimiento de variados aspectos del mundo geológico, geográfico, biológico y cultural.

La consideración de la compleja estructura del espacio simbólico de las culturas originarias nos lleva a varias conclusiones. Primeramente, nos parece que las interpretaciones basadas en perspectivas unilaterales, sea desde las ciencias naturales o sociales, no son suficientes como explicaciones de la riqueza de contenidos que encierran los mitos. Pese a esto, el mito cumple un importante rol orientador en la reflexión crítica del contexto natural y social en el que se desarrollan estas culturas. En general, una prueba de esta función lo constituye el enorme incentivo que han significado los mitos para la investigación arqueológica y geológica, en la búsqueda de preguntas y explicaciones para algunos acontecimientos naturales mencionados en los mitos. En nuestro país, caracterizado por una activa $y$ recurrente dinámica tectónica, los mitos en torno a catástrofes naturales son particularmente interesantes en relación con preguntas geológicas orientadas hacia el esclarecimiento de la historia de erupciones volcánicas, terremotos y maremotos. Desde esta perspectiva, se considera una conclusión importante el énfasis puesto en el valor heurístico que tiene el espacio simbólico que abarca el mito mapuche en el dominio de la antropología, historia, sociología y ciencias naturales.

Subrayar la relevancia que tiene la consideración de la diversidad cultural en la interpretación de los mitos es también un aporte significativo que se desprende de este trabajo. En este sentido, importa reflexionar acerca de los antecedentes históricos que den cuenta de las conexiones y diferencias existentes entre dos matrices distintas de "conocer", la originaria y la occidental, desapercibidas por imposición de una cultura dominante, y marcadas por incomprensión mutua. En este entendimiento, el texto enfatiza la importancia de considerar que, en la cultura mapuche, la relación del hombre con el entorno no está suscrita a la concepción de "naturaleza" de las ciencias naturales actualmente vigente, signada por un concepto de causalidad mecánica y una noción lineal e irreversible del tiempo -fechable, y determinable en referencia a procesos físicos. Si bien esta visión asegura un mayor dominio de las fuerzas naturales, acentúa también el distanciamiento y la creciente escisión entre naturaleza y sociedad humana que marca la modernidad, tendencia que ha sido ampliamente documentada en la literatura, y latamente fundamentada históricamente por Elías (1984). En contraste con la episteme occidental, la cultura mapuche se singulariza en la "participación" simbólica del hombre con el entorno físico y biológico $y$, por ende, en el elevado compromiso entre naturaleza y sociedad; nos recuerda que estamos inmersos "dentro" del mundo natural y nos exhorta así hacia una actitud éticamente más responsable "con la naturaleza", comportamiento inaplazable frente a los graves problemas ecológicos que enfrenta el planeta en la actualidad. En esta perspectiva, se concluye que el conocimiento tradicional, aún vigente en las familias mapuches rurales, constituye un valioso aporte a una forma de habitabilidad humana que incorpora el reconocimiento y cuidado del entorno natural y social.

Finalmente, queremos mencionar que la conexión entre arte, ciencia e historia, que intenta articular muy sucintamente este trabajo, responde a nuestra necesidad de contribuir a la visibilidad del conocimiento mapuche como una cosmovisión integrada de la naturaleza y la cultura -enseñanza que nos parece muy importante rescatar $e$ incorporar al proceso educativo a distintos niveles, sea académico, escolar o social. De no menor importancia es la belleza poética y plástica de los relatos míticos, lo que añade a la enseñanza una 
potencia estética que los constituye como un medio importante para la comunicación y trasmisión de información científica.

\section{AGRADECIMIENTOS}

Por sus valiosos comentarios, se agradece la lectura crítica de Victoria Castro y Antonieta Jerardino de la Universidad de Chile.

\section{BIBLIOGRAFÍA}

Augusta de, F. J. (1903). Gramática Araucana. Valdivia: Imprenta Central J. Lampert.

Augusta de, F. J. (1916). Diccionario Araucano-Español. Tomo 1. Santiago de Chile: Editorial San Francisco.

Barthes, R. (1957). Mitologías. II El mito hoy. Traducción de Héctor Schmucler. Madrid: Siglo Veintiuno de España Editores.

Coña, P. (1930). Lonco Pascual Coña ñi tuculpazugun. Testimonio de un cacique mapuche. Texto dictado al padre Ernesto Wilhelm de Moesbach. $5^{\mathrm{a}}$ Edición. Santiago de Chile. Pehuén Editores.

Denton, G., Heusser, C. J., Lowell, T. V., Moreno, P. J., Andersen, B. G., Heusser, L. E., Schlüchter, C., \& Marchant, D. R. (1999). Interhemispheric Linkage of Paleoclimate during the Last Glaciation. Geografiska Annaler, 81A, 107-153.

Eliade, M. (1963). Mito y realidad. Traducción Luis Gil. Barcelona: Editorial Labor.

Elías, N. (1984). Sobre el tiempo. Traducción de Guillermo Hirata. México: Fondo de Cultura Económica.

Febrès, A. (1765). Arte de la Lengua General del Reyno de Chile. Lima: Editado con Licencia en Lima, en la Calle de la Encarnación.

Foerster, R. (1993). Introducción a la religiosidad mapuche. $2^{\text {a }}$ Edición. Santiago de Chile: Editorial Universitaria.

Góngora de Marmolejo, A. (1862). Historia de Chile desde su descubrimiento hasta el año de 1575. En Colección de Historiadores de Chile y Documentos Relativos a la Historia Nacional. Santiago de Chile: Imprenta del Ferrocarril.

Görgemanns, H. (2004). Platón. Una Introducción. Traducción J. Fernández. Santiago de Chile: Andros Impresores.

Grebe, M. E. (1998). Culturas indigenas de Chile. Un estudio preliminar. Santiago de Chile: Pehuén Editores.

Grifaldo, E. (2012). Estudio comparativo de patologías dentales en series óseas de los siglos XVII y XVIII, del centro de la ciudad de México y del estado de
Tlaxcala. Tesis de la Universidad Nacional Autónoma de México para obtener el título de Cirujana Dentista.

Guevara, T. 1908. Psicolojia del Pueblo Araucano. Imprenta Cervantes. Santiago de Chile, pp. 402.

Guevara, T. (cfr. 2003). El Pueblo Mapuche. Biblioteca Virtual Universal Miguel de Cervantes, Editorial del Cardo.

Gusinde, M. (1916). Medicina e higiene de los antiguos araucanos. II Las enfermedades y la higiene de los mapuches (pp. 177-293). Santiago de Chile: Publicaciones del Museo de Etnología y Antropología de Chile.

Hernández, J. (2009). Noción de verdad en el juicio a los brujos de Chiloé (1880-1881): un ejercicio de contrahistoria. Intersecciones, 2, 38-45.

Jiménez, J. F., \& Alioto S. L. (2007). Relaciones peligrosas: viajes, intercambio y viruela entre las sociedades nativas de las pampas (frontera de Buenos Aires, siglo XVIII). XI Jornadas Interescuelas-Departamentos de Historia, Universidad Nacional del Tucumán, 19 al 22 de septiembre de 2007.

Koessler, B. (1997). Cuentan los araucanos. 2 $2^{\text {a }}$ Edición. Buenos Aires: Editorial Nuevo Extremo.

Kuschel, C. I., Meyer Rusca, W., \& de Moesbach E. W. (1997). Apellidos Huilliches, Mapuches, Pehuenches. Santiago de Chile: Centro Gráfico Prisma.

Lang, N. J., Roe K. J., Renaud C. B., Gill H. S., Potter I. C., Freyhof J., Naseka P.,... \& Mayden R. L. (2009). Novel Relationships among Lampreys (Petromyzontiformes) Revealed by taxonomically Comprehensive Molecular Data Set. American Fisheries Society Symposium 72.

Leiva, R. A. (2013). Maremoto de 1960, sacrificio humano y restablecimiento del equilibrio en el Wallmapu. Investigaciones Sociales, 17(30), 35-45.

Lenz, R. (1912). Tradiciones e ideas de los araucanos acerca de los terremotos. Anales Universidad de Chile, 130, $23 \mathrm{pp}$.

Lévi-Strauss, C. (1968). Mitológicas: El origen de las maneras de Mesa. Traducción Juan Almela. México: Siglo XXI Editores S.A.

Masse, W. B., \& Masse, M. J. (2004). Myth and Catastrophic Reality: Using Cosmogonic Mythology to identify cosmic Impacts and Massive Plinian Eruptions in Holocene South America. Symposium, "Myth and Geology", 32 International Geological Congress, August 2004, Florence, Italy.

Masse, W. B., Barber, W. E., Piccardi, L., \& Barber, P. T. (2007). Exploring the nature of myth and its role in science. En L. Piccardi \& W. B. Masse (Eds.), Myth and Geology. Special Publication (pp. 9-28). London: 
Geological Society.

Mösbach, E.W. [ Botánica Indígena de Chile. En C. Aldunate \& C. Villagrán (Eds.) (140 p.) Santiago de Chile: Editorial Andrés Bello.

Neira, F. J. (1984). Biomorfología de las lampreas parásitas chilenas Geotria australis Gray 1851 y Mordacia lapicida Gray 1851 (Petromyzontiformes). Gayana Zoológica, 48, 30-40.

Ñanculef, H. J. (2004a). La civilización mapuche. Astronomía ciencia y Cosmovisión. Diaporama Inscrito en Derecho Intelectual $\mathrm{N}^{\circ} 1069462$.

Nanculef, H. J. (2004b). El sistema médico y la herbolaria mapuche. Un Enfoque desde su Cosmovisión. Diaporama Inscrito en Derecho Intelectual $\mathrm{N}^{\circ}$ 1069462.

Plath O. (1994). Geografía del mito y la leyenda chilenos. Santiago de Chile: Editorial Grijalbo S.A.

Plath, O. (1995). Lenguaje de los pájaros chilenos. Santiago de Chile: Editorial Grijalbo S.A.

Petit-Breuilh, M. E. (2006). Naturaleza y desastres en hispanoamérica. La visión de los indígenas. Madrid: Sílex Universidad.

Platon. Diálogos: República; Político; Timeo; Critias; Leyes. Tomos IV, V, VI, VII, VIII. Editorial Gredos, Madrid, 2000-2007.

Potter, I. C., \& Strahan R. (1968). The taxonomy of the Lampreys Geotria and Mordacia and their distribution in Australia. Proceedings of the Linnean Society of London, 179, 229-240.

Potter, I. C., Gill, H. S., Renaud, C. B., \& Haoucher, D. (2015). The Taxonomy, Phylogeny, and Distribution of Lampreys. Lampreys Biology, Chapter, 2, 35.

Ramírez, C. (1995). Onomástica indígena de Chile: Toponimia de Osorno, Llanquihue y Chiloé. Valdivia: Imprenta Universitaria.

Reyes, P., Vázquez, M., \& Hüne, M. (2014). La relación del filoko o lamprea de bolsa (Geotria australis) con la comunidad mapuche de Gorbea, sur de Chile; una mirada desde la antropología y la biología marina (pp. 1-16). XXXIV Congreso de Ciencias del Mar de la
Sociedad Chilena de Ciencias del Mar, conjuntamente con la Universidad de Lagos, Osorno 26 y el 30 de mayo del 2014.

Rosales de, D. (1877). Historia General del Reyno de Chile. Flandes Indiano. Valparaíso: Imprenta del Mercurio.

Rosete, F. (2006). Aby Warburg: moderno katharmós. Andamios, 4(2), 275-277.

Ruiz, R. (1995). Poétique du cinema. Éditions Dis-Voir, Paris. Traducción y Ampliado Waldo Rojas "Poética del Cine". Santiago de Chile: Editorial Sudamericana Chilena.

Valdivia de, L. (1648). Arte y gramática general de la lengua que corre en todo el Reyno de Chile. Con un Vocabulario y Confesionario. Con Licencia de Thomás Lopéz de Haro, Sevilla.

Villagrán, C. (1998). Etnobotánica indígena de los bosques de Chile: sistema de clasificación de un recurso de uso múltiple. Revista Chilena de Historia Natural, 71, 245-268.

Villagrán, C., Villa, R., Hinojosa, L. F., Sánchez, G., Romo, M., Maldonado, A., Cavieres, L.,... \& Valenzuela, A. (1999). Etnozoología Mapuche: un estudio preliminar. Revista Chilena de Historia Natural, 72, 595-627

Villagrán, C., \& Hinojosa, L. F. (2005). Esquema biogeográfico de Chile. En J. Llorente \& J. Morrone (Eds.), Regionalización biogeográfica en Iberoamérica y tópicos afines. México D. F.: Universidad Nacional Autónoma de México.

Villalobos de, C., Zanca, F., \& Ibarra-Vidal, H. (2005). Redescription and new records of freshwater Nematomorpha (Gordiida) from Chile, with the description of two new species. Revista Chilena de Historia Natural, 78, 673-686.

Vitaliano, D. B. (2007). Geomythology: Geological origins of myths and legends. En L. Piccardi \& W. B. Masse (Eds.), Myth and Geology. (pp. 1-7). Special Publication 273. London: Published by the Geological Society.

Warburg, A. (1923). El ritual de la serpiente. Epilogo. Ulrich Raulff. Trad. Joaquín Etorena Homaeche. México: Sexto Piso. 